\title{
Determination of the Frictional Behavior at Compaction of Powder Materials Consisting of Spray-Dried Granules
}

\author{
Hjalmar Staf, Erik Olsson (D, Per Lindskog, and Per-Lennart Larsson
}

\author{
(Submitted July 6, 2017; in revised form October 12, 2017; published online February 2, 2018)
}

\begin{abstract}
The frictional behavior during powder compaction and ejection is studied using an instrumented die with eight radial sensors. The average friction over the total powder pillar is used to determine a local friction coefficient at each sensor. By comparing forces at compaction with forces at ejection, it can be shown that the Coulomb's friction coefficient can be described as a function of normal pressure. Also stick phenomena has been investigated in order to assess its influence on the determination of the local friction coefficient.
\end{abstract}

Keywords Coulomb friction, cutting inserts, die friction, FEM, finite element simulations, granular powder, powder compaction, reverse engineering, stick, wall friction, WC-Co powder

\section{Introduction}

During powder compaction, powder is exposed to a frictional force $F_{\mathrm{f}}$, acting perpendicular to the normal force $F_{\mathrm{N}}$ at contact with the pressing tool. Frictional forces have a huge impact on the density gradient after pressing of powders spray dried and compacted to roughly half its sintered density, for instance cemented carbide powder with WC-Co and PEG (Ref 1-4). Density gradients in powder compacts (green bodies) result in shape distortion after sintering, often resulting in expensive and time-consuming redesigns of pressing tools. To predict the shape after sintering for press tool compensation, finite element (FE) simulations have proven to be a useful tool (Ref 5). It has been shown (Ref 6,7) that friction has a major impact on the shape after sintering and consequently it is important to include this feature accurately in the abovementioned FE simulations of the pressing process.

Since forces during compaction are highly nonlinear and much lower in the beginning of the pressing process, also the frictional behavior at low forces is important to consider. In Guyoncourt et al. (Ref 8), an instrumented die has successfully been used to determine the frictional behavior between die and powder, but for low forces, corresponding to more than half of the compaction step, a possible artifact could be seen. In the mentioned study, friction is assumed to be a function of normal pressure, even though a variation with density could not be

Hjalmar Staf, Department of Solid Mechanics, Royal Institute of Technology, 10044 Stockholm, Sweden and Sandvik Coromant AB, R\&D, 12680 Stockholm, Sweden; Erik Olsson, Department of Solid Mechanics, Royal Institute of Technology, 10044 Stockholm, Sweden and Department of Civil and Architectural Engineering, Royal Institute of Technology, 10044 Stockholm, Sweden; Per Lindskog, Sandvik Coromant AB, R\&D, 12680 Stockholm, Sweden; and Per-Lennart Larsson, Department of Solid Mechanics, Royal Institute of Technology, 10044 Stockholm, Sweden. Contact e-mails: erolsson@kth.se and plla@kth.se.

ruled out. For the cemented carbide powder used in the above study, the Coulomb friction coefficient started at 0.2 and decreased with increasing normal pressure. The compaction behavior of iron powder has also been successfully investigated with an instrumented die in Hong et al. (Ref 9).

Research using a so-called two-step test method to define the friction coefficient between WC-Co powders and die proposes the coefficient to be constant 0.2 , obviously relying on Coulomb friction (Ref 10). In the two-step test method, powder is first compacted and then removed and pushed against a moving die material (Ref 11). A different friction measurement with the same method suggests that friction depends on normal force and displacement, taking on values between 0.2 and 0.4 (Ref 12). A third method, presented in Wikman et al. (Ref 13), compares tests with simulation and uses reverse engineering to define the friction coefficient. In Cameron and Gethin (Ref 14), the die wall friction mechanism is investigated with FE simulations of granules. This method can give a good understanding of the mechanism, even if the friction coefficient itself is hard to determine through this method.

Comparing results from the two-step method with results where an instrumented die has been used to identify the frictional behavior indicates that the two-step method does not give the complete behavior. In contrary to the instrumented die, the friction coefficient is constant with respect to normal pressure when determined with the two-step method in Samuelsson and Bolin (Ref 10). In Wagner (Ref 12), the twostep method suggests an increasing coefficient with increased normal force, also in contrary to results from an instrumented die (Ref 9). It is therefore believed that an extensive study with an instrumented die is needed for this purpose. Since previous studies of the frictional behavior of granular powders with an instrumented die do not analyze the behavior at low normal pressures, this is important to include presently.

In the present study, an instrumented die with eight radial pressure sensors, used in previous research (Ref 15), is considered and shown in Fig. 1 and 2. In contrast to the situation in Lindskog et al. (Ref 15), the die is mounted in a pressing machine with good rate capabilities as discussed in more detail below. It has been shown in Staf et al. (Ref 7) that rate influences die friction. Input from this research is important and useful for future efforts to accurately simulate the pressing behavior of the presently analyzed powders. Together with the results presented in previous research (Ref 6, 16-18), it is 


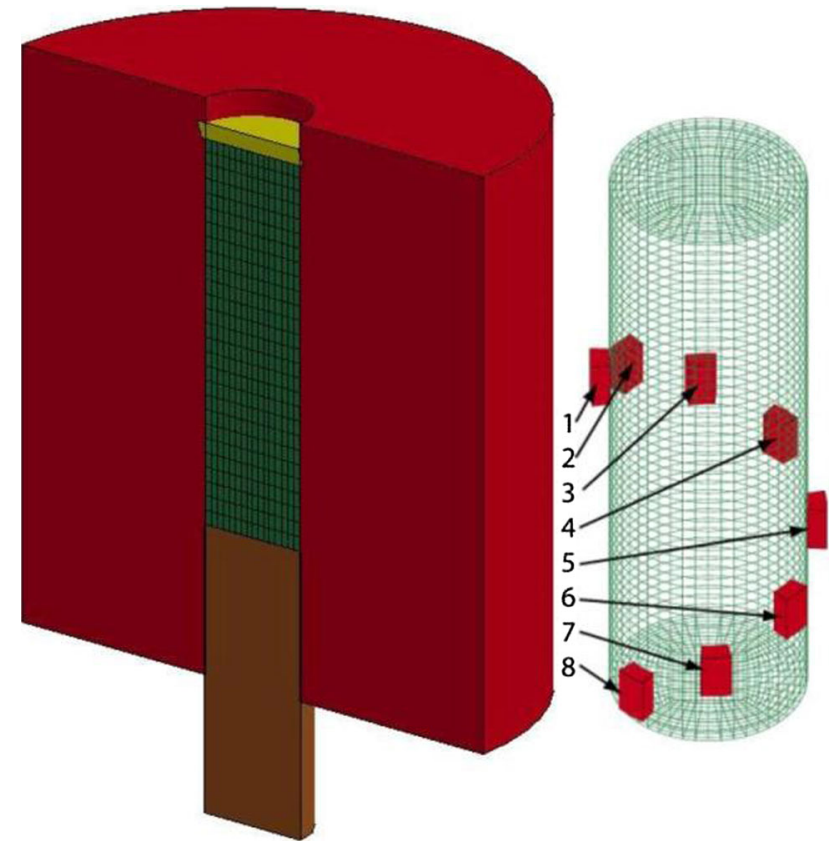

Fig. 1 Schematic picture of the instrumented die used in the tests. The sensors (marked 1-8) are positioned in a helical pattern around the powder pillar (green squares) (Color figure online)

believed that future FE simulations will give relevant results for the press tool compensations mentioned above. Both FE simulations of powder compaction (Ref $5,19,20)$ as well as simulations using the discrete element method (DEM) (Ref 2124) can in the future gain from the present results.

\section{Analysis}

A typical pressure graph from a cycle with loading, holding, and unloading can be seen in Fig. 3. Two representative sensors are chosen. The pressure for sensor 4 decreases to zero when the punch has passed the sensor. During holding time, there is a pressure drop, which can be described as relaxation (Ref 7).

Initially, average friction over the total powder pillar is considered. The total friction force $F_{\mathrm{f}}$ and the total normal force $F_{\mathrm{N}}$ are used to calculate an average Coulomb's friction coefficient $\mu_{\text {avg }}$ according to the relation

$\mu_{\mathrm{avg}}=\frac{F_{\mathrm{f}}}{F_{\mathrm{N}}}$.

Even if the height/diameter ratio is quite small, it is certainly the local (real) friction coefficient $\mu$ that is relevant to define. Since there are eight radial sensors, a semi-local friction over each sensor is determined with reverse engineering, from now on called optimized local friction coefficient $\mu_{\text {opt }}$. The parameter $\mu_{\mathrm{opt}}$ is optimized so that the resulting average friction coefficient $\mu_{\text {avg }}$ coincides with the experimental $\mu_{\text {avg }}$ according to

$\mu_{\mathrm{avg}}=\frac{F_{\mathrm{f}}}{F_{\mathrm{N}}}=\frac{2 \pi R \int_{0}^{H} p(h) \cdot \mu(p(h)) \mathrm{d} h}{2 \pi R \int_{0}^{H} p(h) \mathrm{d} h} \approx \frac{\sum_{i=1}^{8} p_{i} \cdot \mu\left(p_{i}\right)_{\mathrm{opt}} h_{i}}{\sum_{i=1}^{8} p_{i} h_{i}}$

for a given powder pillar height $H . p(h)$ is the normal pressure at position $h$, being zero at the position of the moving

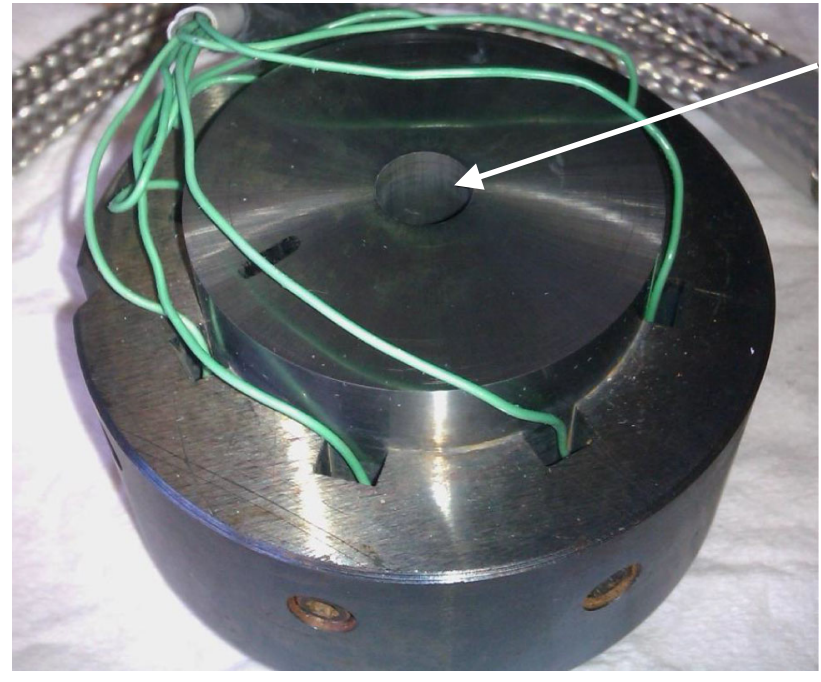

Fig. 2 Picture of the instrumented die before mounting in the pressing machine. Arrow indicates the die cavity

punch, and $p_{i}$ the normal pressure at sensor $i$. The sum is taken over sensors $1-8$, and $h_{i}$ is the powder pillar height corresponding to sensor $i$, which is zero when the punch has passed sensor $i . R$ is the radius of the die cavity. Different functions to describe the optimized local friction coefficient $\mu_{\text {opt }}$ have been used in the optimization loop. In section 2, the functions yielding good agreement for the frictional behavior are presented.

To determine whether friction can be described as a function of normal pressure $p$ alone, $\mu_{\mathrm{avg}}$ is also calculated during ejection with different average density and normal pressure. In addition, total friction force $F_{\mathrm{f}}$ during ejection is calculated from the local sensor pressure

$F_{\mathrm{f}} \approx \sum_{i=1}^{8} p_{i} \cdot \mu\left(p_{i}\right)_{\mathrm{opt}} A_{i}$

and compared with the measured $F_{\mathrm{f}} . A_{i}$ is the die cavity area corresponding to sensor $i$.

A possible influence on the result from stick phenomena is considered using the relation

$F_{\mathrm{f}}=\left\{\begin{array}{cc}K_{\mathrm{T}} \delta_{\mathrm{T}} & \text { if } K_{\mathrm{T}} \delta_{\mathrm{T}} \leq \mu p \\ \mu p & \text { if } K_{\mathrm{T}} \delta_{\mathrm{T}}>\mu p\end{array}\right.$

for the friction force and assuming that the displacement $\delta_{\mathrm{T}}$ is linearly decreasing from the moving punch and up. $K_{T}$ is chosen so that at least two sensors are experiencing stick, which is extremely conservative since stick occurs at the end of pressing when two sensors cover $50 \%$ of the powder pillar. It should be mentioned that the characteristic "stick-slip sound" did not appear since pressing rate was chosen well above this effect. In the same manner as described above, the local friction $\mu_{\text {opt }}$ is optimized from the average friction $\mu_{\text {avg }}$ by inserting Eq 4 in 2.

\section{Test Setup}

The same instrumented die as used in previous research (Ref $15)$ is in the present experiments mounted in an electrical production pressing machine. Maximum loading and ejection rate is $200 \mathrm{~mm} / \mathrm{s}$, and maximum acceleration and deceleration 


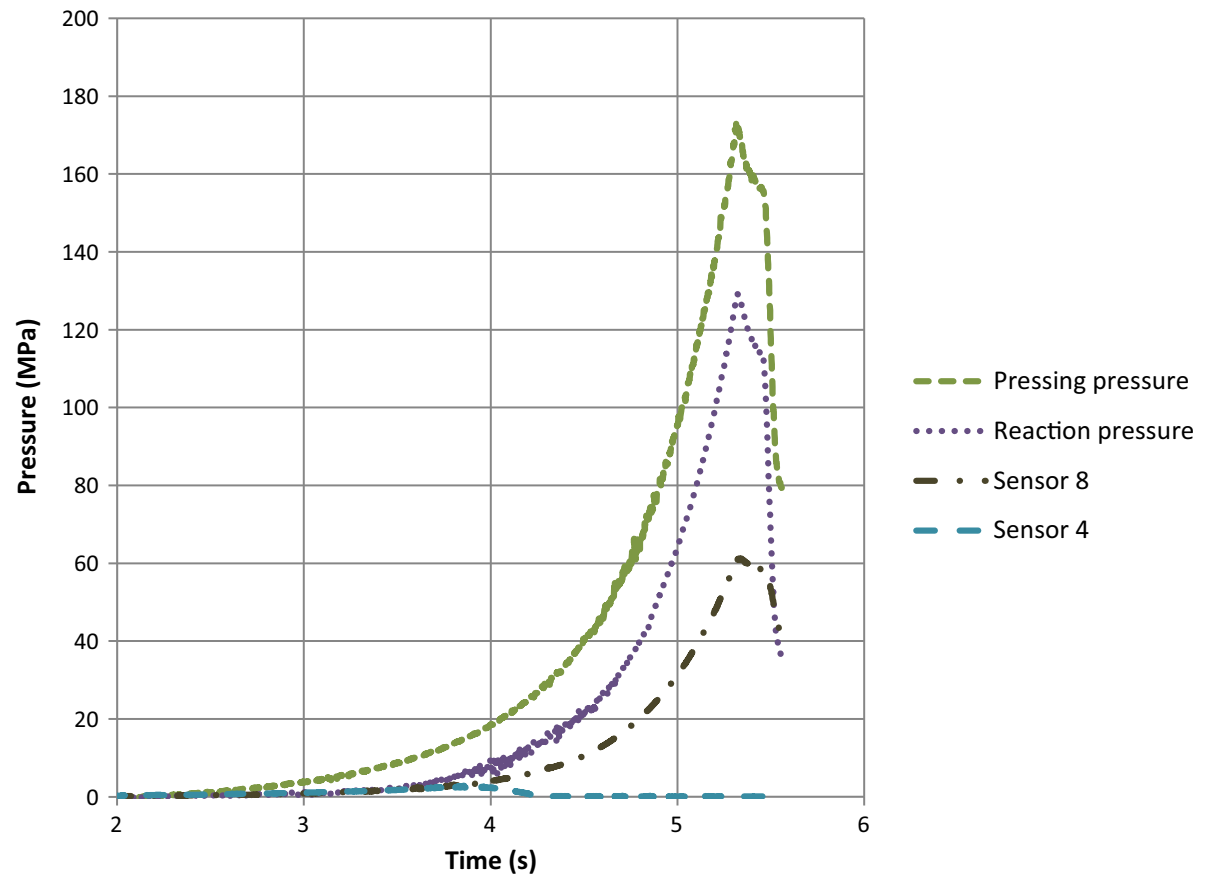

Fig. 3 Typical pressure graph from loading, holding, and unloading of Powder A. The characteristics of pressing pressure, reaction pressure, and two typical sensor pressures are presented

is $3 \mathrm{~m} / \mathrm{s}^{2}$. Pressing forces are measured in the machine with accuracy better than $0.5 \%$. The powder is compacted to a height of $10 \mathrm{~mm}$. After filling, eight sensors are in contact with the powder, and after complete compaction, four sensors are in contact. The cavity radius, $R$, is $5 \mathrm{~mm}$.

Details of the instrumented die can be found in Lindskog et al. (Ref 15). Figure 1 shows schematically how the sensors are positioned, and Fig. 2 shows the die before mounting. It is made from hard metal with a steel ring shrunk onto the die. Holes for the sensors are machined and the sensor tips and the inner surface of the die are treated together using electrical discharge machining (WEDM) in order to make sure that the surface is smooth and that the sensors are in fact measuring directly on the surface of the powder material. The radial stress measurements are carried out through using eight pressure sensors, Kistler sensor type 6183A, that are positioned in a helical pattern around the cylindrical powder cavity. The principle of the sensor measurement is to produce a charge proportional to the pressure applied "in the direction of the sensor pin" by means of a quartz element. The sensors are connected to a charge amplifier, Kistler charge amplifier type 5048A082, and the charge measured by a sensor is scaled according to the calibrated sensitivity of the specific sensor. The combination of the amplifier and the sensors gives a pressure range during the measurements, which varies between 0-218 $\mathrm{MPa}$ and 0-234 MPa for individual sensors. At the maximum pressure values, the sensors have a maximum of $0.5 \%$ FSO linear deviation. In contrast to previous study (Ref 15), the amplifier is connected to a USB-6343 from National Instruments and signals are recorded with a rate of $1 \mathrm{~ms}$. Also the pressing forces are recorded in this device.

Powder A and Powder B used in the experiments are spraydried WC-Co mixtures also used in previous research (Ref 7, 16-18, 21). The average particle size for Powder A is smaller than Powder B, which typically leads to higher press forces to achieve a given relative material density. They have both roughly $2 \%$ pressing agent PEG. SEM images of the powders are previously presented in Olsson and Larsson (Ref 24). During compaction, the powder volume is decreased to about half the original powder volume.

\section{Result and Discussion}

As described in section 2, the average friction $\mu_{\text {avg }}$ over the entire powder pillar and the local friction with respect to each sensor $\mu_{\mathrm{opt}}$ are determined. Figure 4 shows the average friction coefficient for two experiments on Powder A (described in section 1.2). It can clearly be seen by simple inspection that the accuracy is better at higher normal pressure where the oscillations of results are relatively lower. In Fig. 5, friction is presented as a function of average relative density $d$ (average density divided by sintered density). Both figures show that the friction coefficient has a clear maximum. The physical explanation for the existence of such maxima is as follows: At low pressure values, sliding of the material against the wall is facilitated by particle rearrangement leading to a low friction coefficient. As the pressure increases, rearrangement is gradually reduced and the particles are locked in contact and the friction coefficient increases up to a maximum value corresponding very approximately to polymer (binder) - metal contact. At even higher pressures, the powder compact slowly becomes a homogeneous (porous) material with the value on the friction coefficient approaching standard values for metalmetal contact $(0.1-0.2)$.

The function used to describe the local friction coefficient $\mu_{\mathrm{opt}}$ is for simplicity chosen linear for low normal pressure 
since the accuracy in the experimental data is lower in that region. For higher normal pressures, a power function and a logarithmic function are chosen. A maximum value is added to the function and also optimized. The optimized power function for the local friction coefficient is

$\mu_{\mathrm{opt}}= \begin{cases}a_{1}+a_{2} \cdot p & \text { if } p<p_{1} \\ a_{3} & \text { if } p_{1} \leq p \leq p_{2} \\ \left(p / a_{4}\right)^{-a_{5}} & \text { if } p>p_{2}\end{cases}$

where parameters are presented in Table $1, p_{1}$ is $1.1 \mathrm{MPa}$, and $p_{2}$ is $2.5 \mathrm{MPa}$. The logarithmic function is

$\mu_{\mathrm{opt}}= \begin{cases}a_{1}+a_{2} \cdot p & \text { if } p<p_{1} \\ a_{3} & \text { if } p_{1} \leq p \leq p_{2} \\ b_{4}+b_{5} \ln (p) & \text { if } p>p_{2}\end{cases}$

where $a_{1-3}$ is same as in $\mathrm{Eq} 5, b_{4}$ is 0.545 , and $b_{5}$ is $0.097 \ln (\mathrm{MPa})^{-1} \cdot p_{1}$ is $1.1 \mathrm{MPa}$ and $p_{2}$ is $1.75 \mathrm{MPa}$. Both optimized functions are shown in Fig. 6. In Fig. 7, the average friction $\mu_{\text {avg }}$ from one test is presented together with corresponding average friction coefficient recalculated according to Eq 2 with above $\mu_{\text {opt }}$. It is clear from the figure that the power function better describes the local frictional behavior. Comparing Fig. 6 and 7, it is obvious that local and average friction coefficients coincide well in the present experiments.

The average friction coefficient $\mu_{\text {avg }}$ during ejection for different densities and normal forces is presented in Fig. 8 and
9 and compared with average friction during one loading test. The result shows that the friction coefficient is best described as a function of normal pressure. The friction coefficient values show a clear difference between loading and ejection when plotted with respect to average relative density $d$, leading to the conclusion that this measure cannot be used to describe the frictional behavior as the values on the friction coefficient become test dependent in this case. It can therefore be concluded that $\mu=\mu(p)$. The sum of the local friction force is compared with the experimentally determined one according to Eq 3 in Fig. 10. From this, it can be further established that $\mu=\mu(p)$ is valid for the local friction coefficient.

As discussed previously in the above sections, influence from stick contact is also analyzed. It is then conservatively assumed that two sensors at the end of compaction are in stick, which is $50 \%$ of the powder pillar, which results in a value of $K_{\mathrm{T}}$ of $240 \mathrm{MN} / \mathrm{m}$. The friction coefficient curve $\mu_{\text {opt }}$ then gets the shape presented in Fig. 11, and taking into account the extreme assumption discussed above, any effect from stick can definitely be ruled out. In addition, it could be mentioned that the friction coefficient defined during ejection of the green body shows almost equal friction coefficient at the same normal pressure, even though the whole powder pillar is moving in this case. This of course further confirms the finding that stick phenomena are negligible when using the present experimental setup.

Table 1 Optimized parameters describing the local friction coefficient $\mu_{\text {opt }}$ with Eq 5

\begin{tabular}{lccccc}
\hline & $\mathbf{a}_{\mathbf{1}}[-]$ & $\mathbf{a}_{\mathbf{2}}\left[\mathbf{M P a}^{-1}\right]$ & $\mathbf{a}_{\mathbf{3}}[-]$ & $\mathbf{a}_{\mathbf{4}}[\mathbf{M P a}]$ & $\mathbf{a}_{\mathbf{5}}[-]$ \\
\hline Powder A & -0.036 & 0.48 & 0.49 & 0.30 & 0.33 \\
Powder B & -0.070 & 0.48 & 0.40 & 0.080 & 0.29 \\
\hline
\end{tabular}

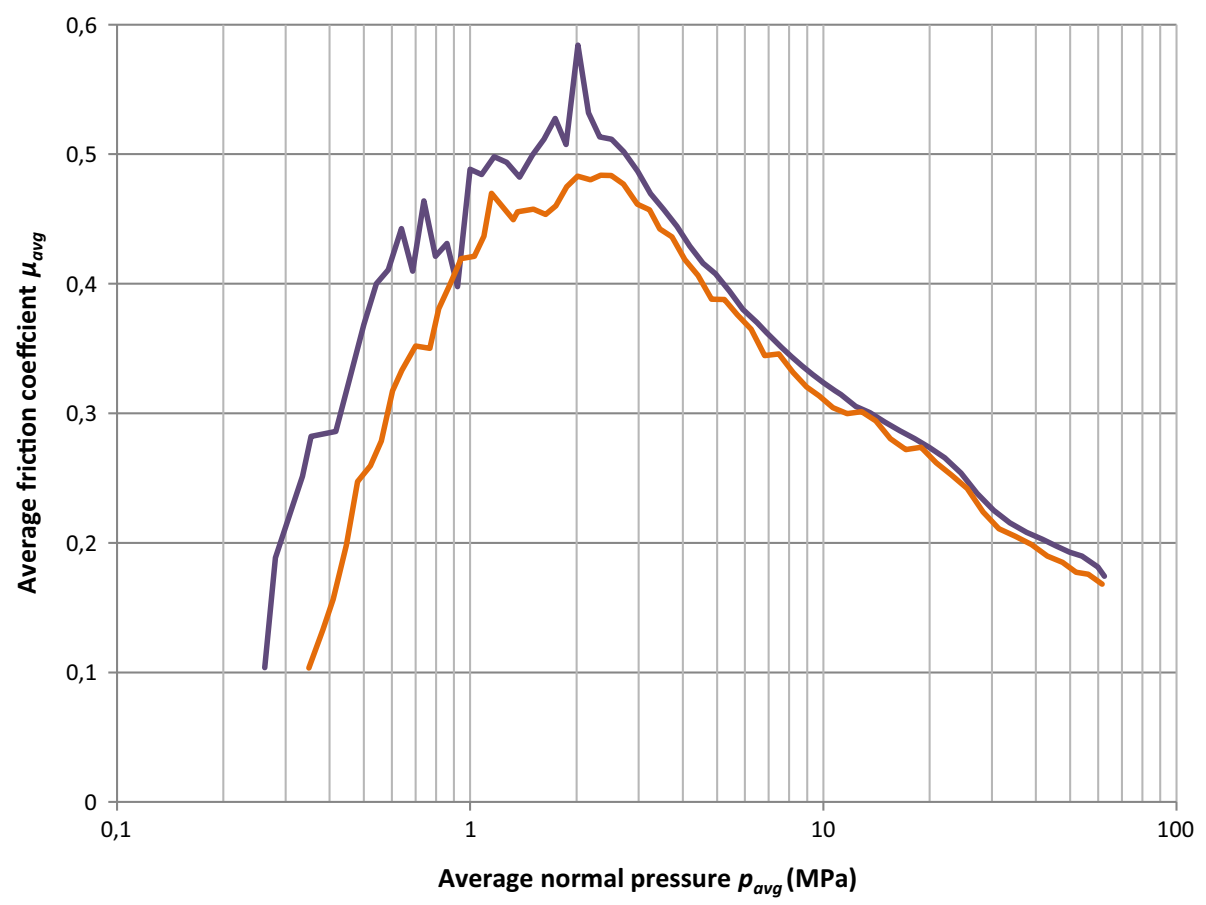

Fig. 4 Average friction coefficient $\mu_{\text {avg }}$ during loading as a function of average normal pressure. The graph shows the result from two experiments on Powder A 


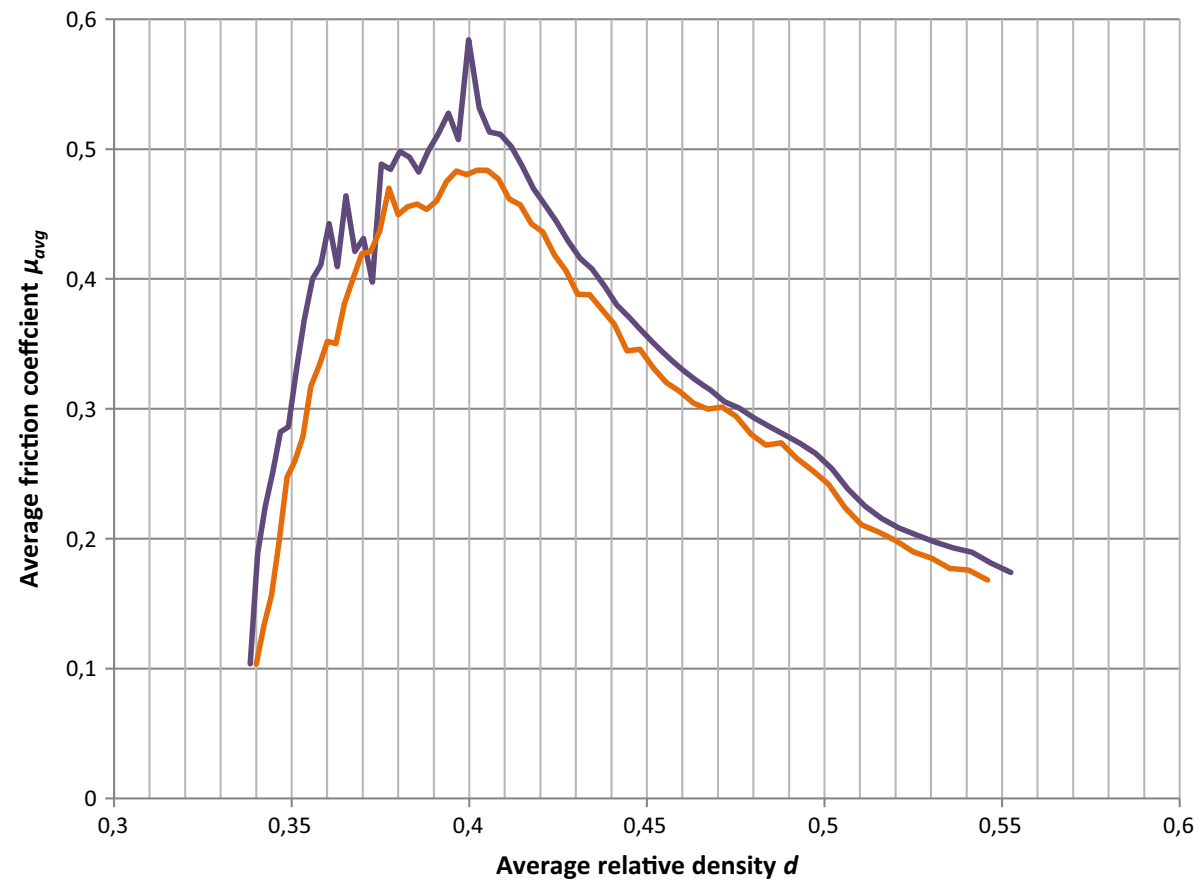

Fig. 5 Average friction coefficient $\mu_{\text {avg }}$ during loading as a function of relative density $d$ (density divided by sintered density). Result from two experiments on Powder A

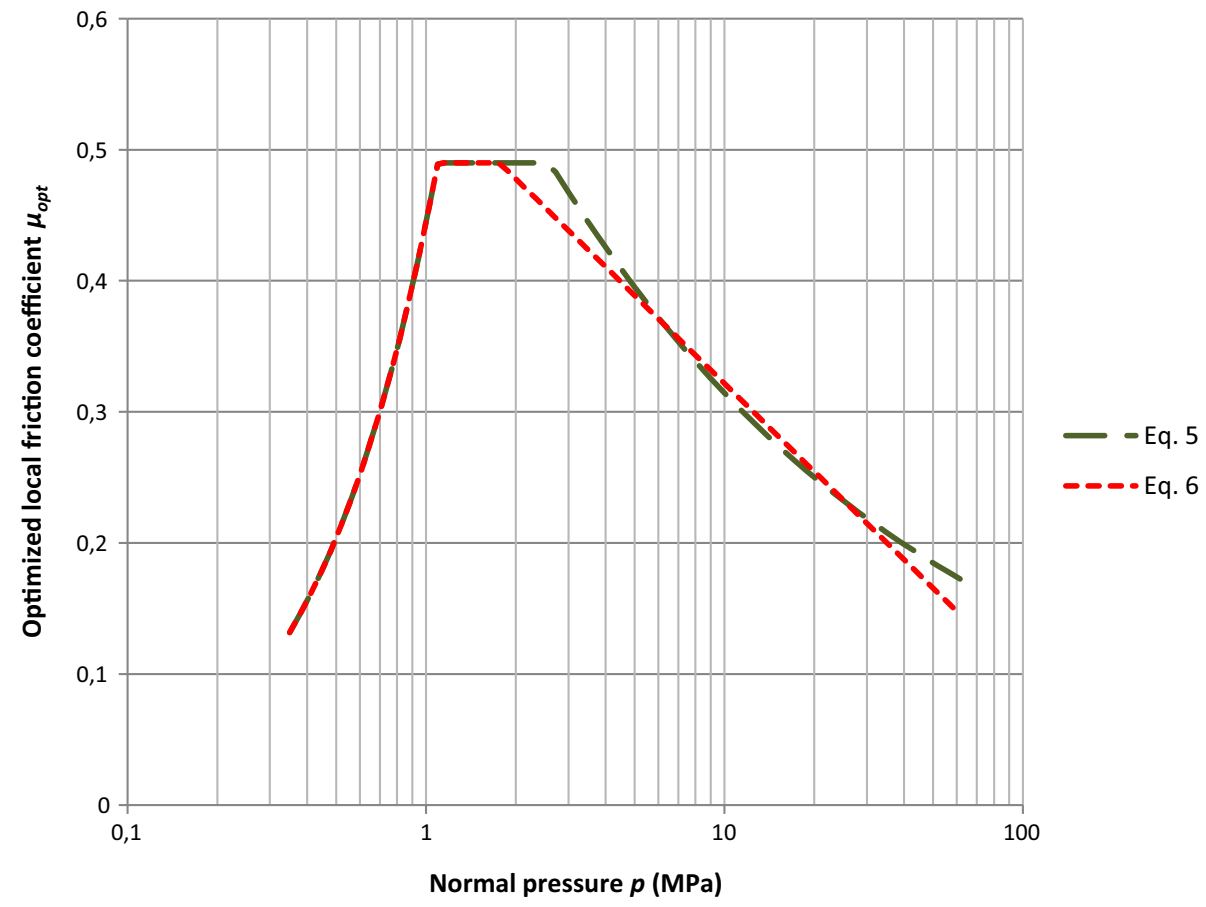

Fig. 6 Optimized local friction coefficient $\mu_{\text {opt }}$ for Powder A based on two different functions

In Fig. 12, the average friction coefficient $\mu_{\text {avg }}$ determined directly from a test and recalculated with $\mu_{\mathrm{opt}}$ and $\mathrm{Eq} 2$ for Powder B is presented and compared with the corresponding results for Powder A. The parameters for calculating the local optimized friction coefficient using Eq 5 are presented in Table 1. The influence of different particle size in Powder B results in a lower friction coefficient. Indeed, this gives further confidence in the presently proposed approach for determining the local frictional behavior.

The experimental results in Fig. 13 show the influence of different compaction rates on the friction coefficient. It is clear that higher rate gives rise to lower friction also way above rates where stick-slip phenomena could be an issue. This result is in line with the findings presented in Staf et al. (Ref 7), where it 


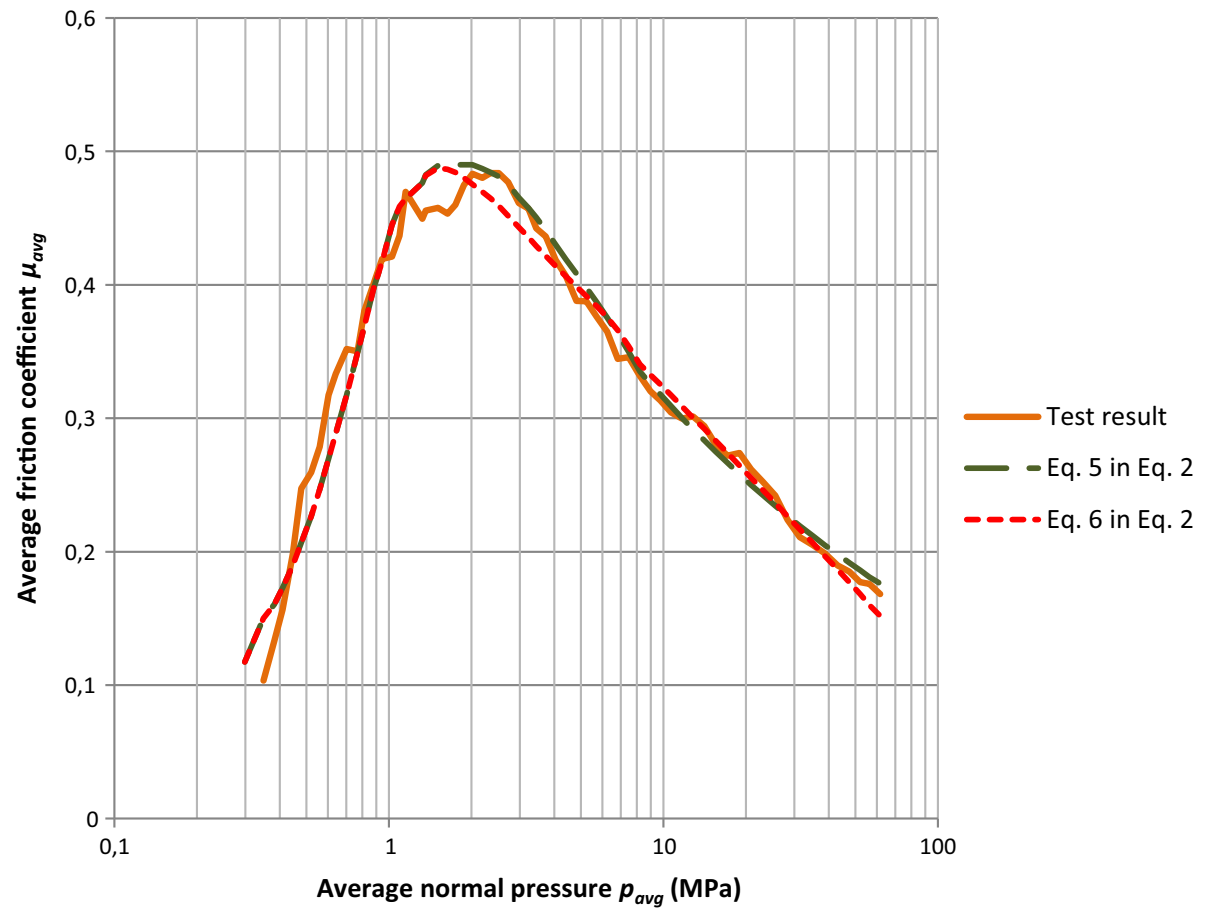

Fig. 7 Average friction coefficient $\mu_{\text {avg }}$ over total powder pillar from a loading test calculated according to Eq 1, respectively, Eq 2 with the two optimized functions

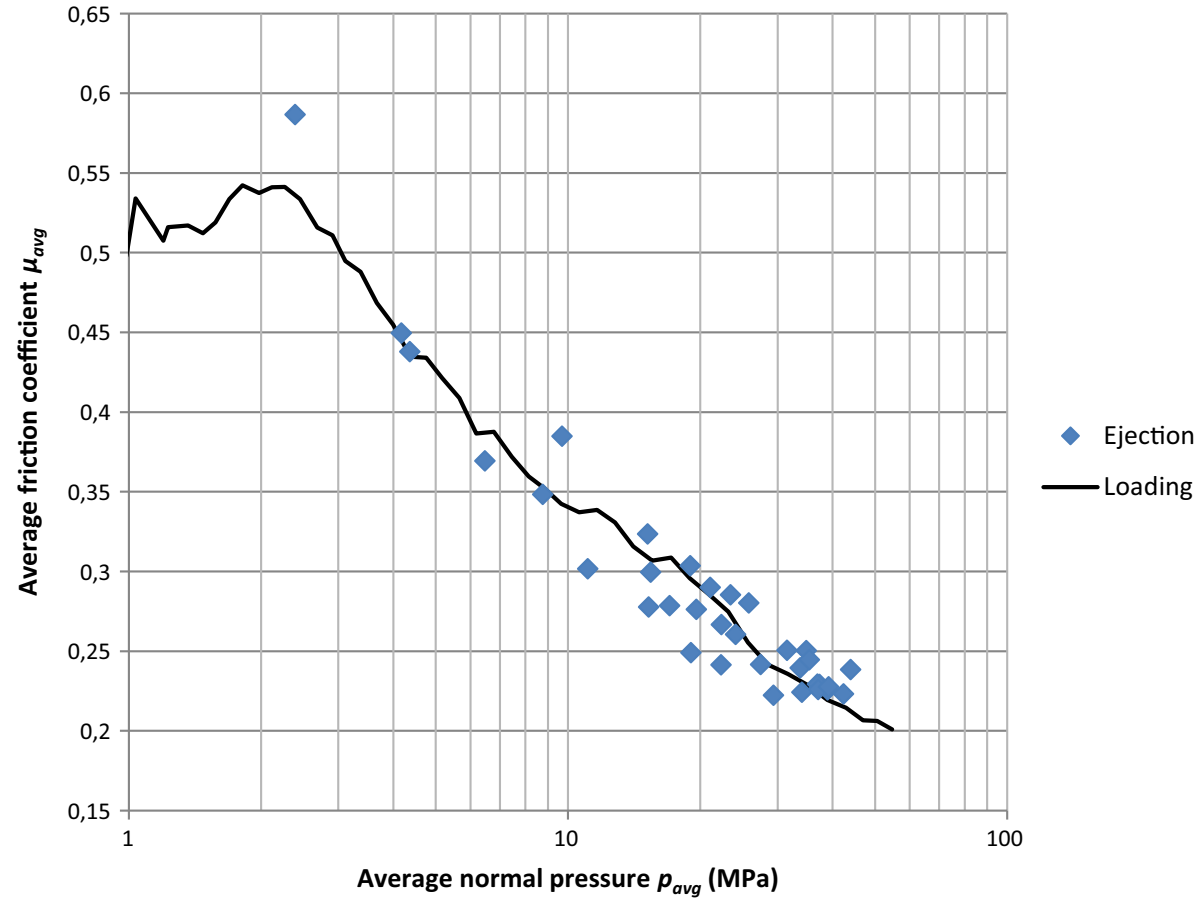

Fig. 8 Average friction coefficient $\mu_{\text {avg }}$ from one loading test compared with $\mu_{\text {avg }}$ from 34 ejection tests with different average densities and different normal pressures presented as a function of normal pressure

was shown that a less uneven shrinkage during sintering is present when the green body is compacted at higher rate, which could be explained by a lower friction coefficient.

It should also be mentioned that commercial FE software, for instance Abaqus and LS-Dyna, has contact formulations that gives the possibility to define a friction coefficient that is a function of normal pressure (Ref 25, 26). Since normal forces are highly nonlinear, contact formulations are for that reason still challenging. 


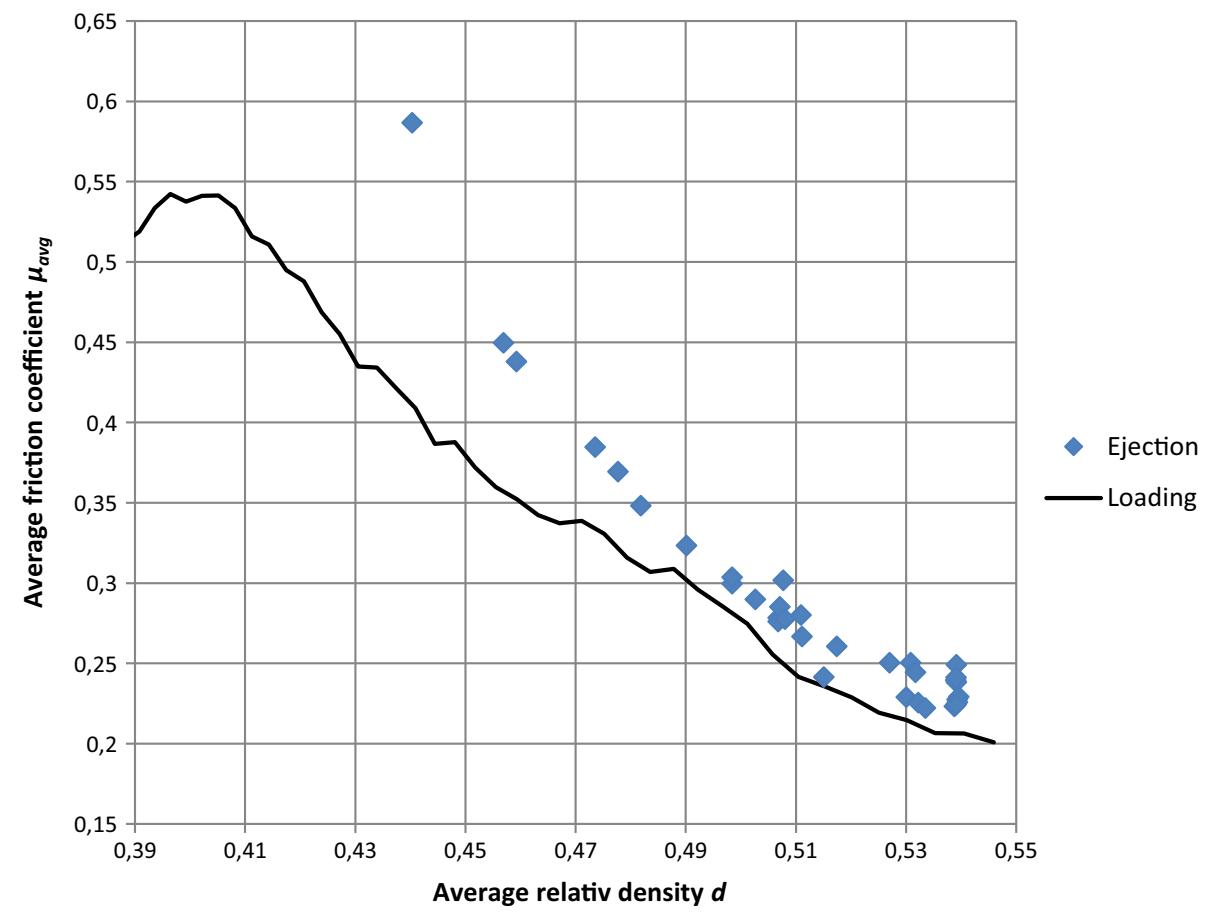

Fig. 9 Friction $\mu_{\text {avg }}$ from one loading test compared with $\mu_{\text {avg }}$ from 34 ejection tests presented as a function of relative density $d$

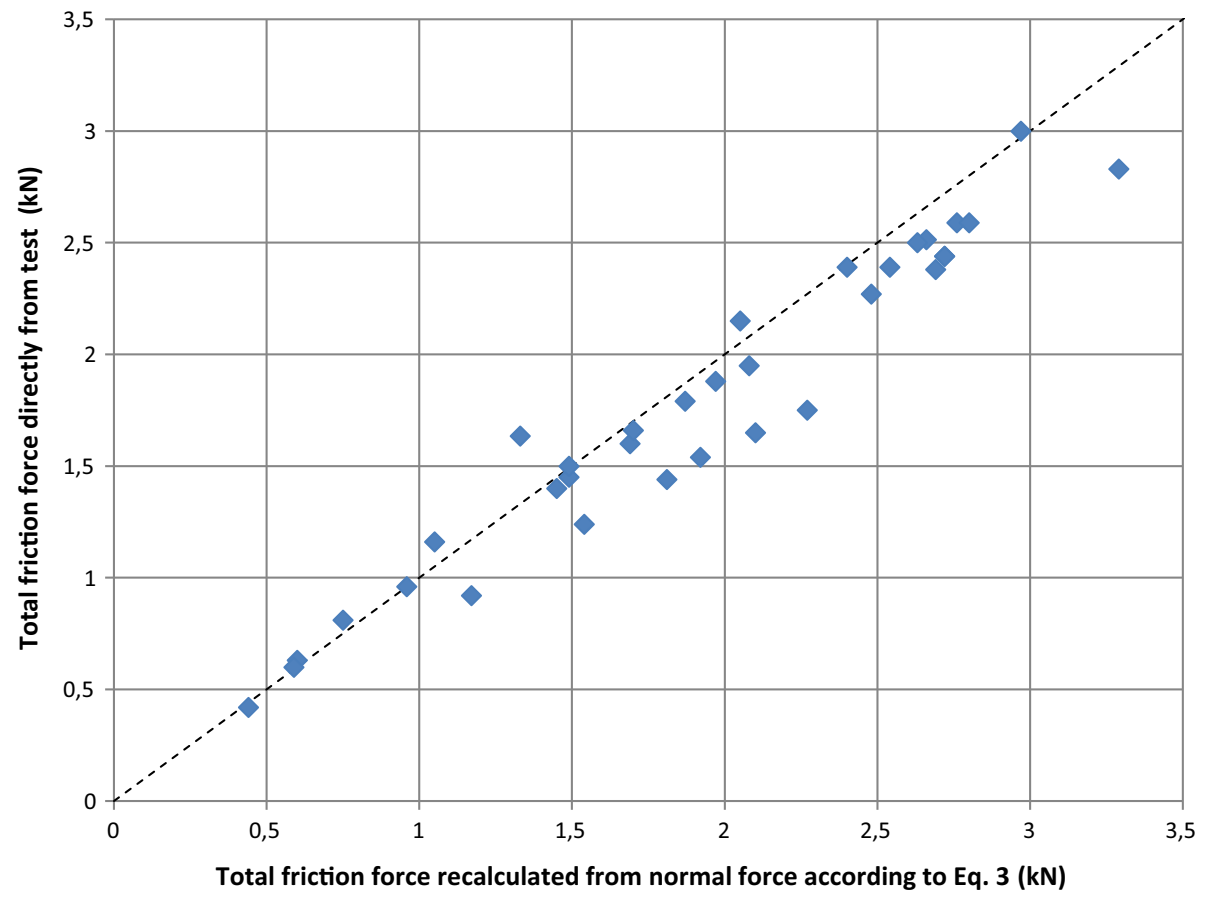

Fig. 10 Total friction force during ejection compared with the equivalent recalculated force from sensor pressure according to Eq 3 . Dotted line corresponds to a situation where the two forces are equal

\section{Conclusion}

The present analysis shows that the friction coefficient pertinent to a powder material can be determined during powder compaction using an instrumented die. The result from the present research is listed below.

- A method to calculate the local (real) friction coefficient from the average coefficient, determined during die press- 


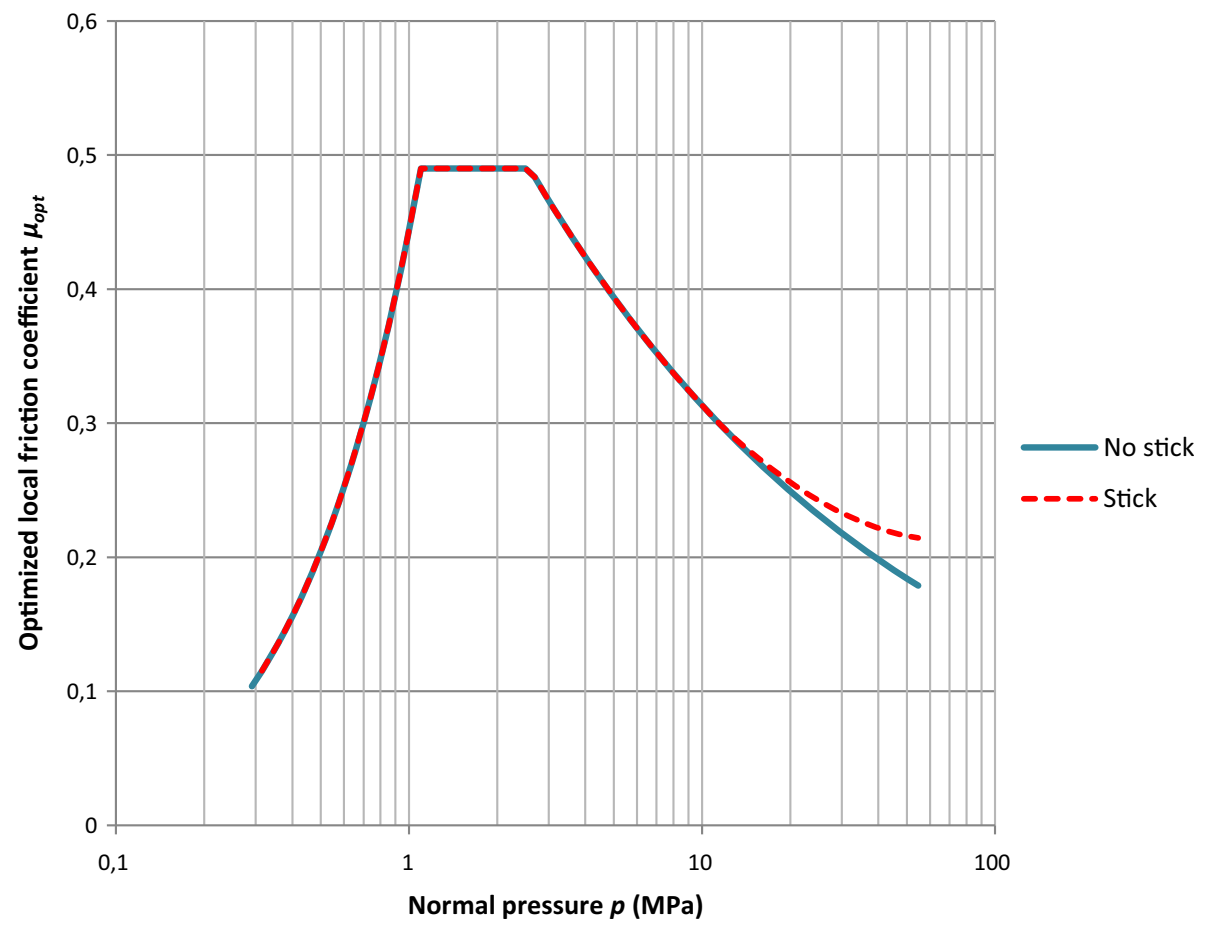

Fig. 11 Optimized local friction coefficient if stick is assumed at up to $50 \%$ of powder pillar

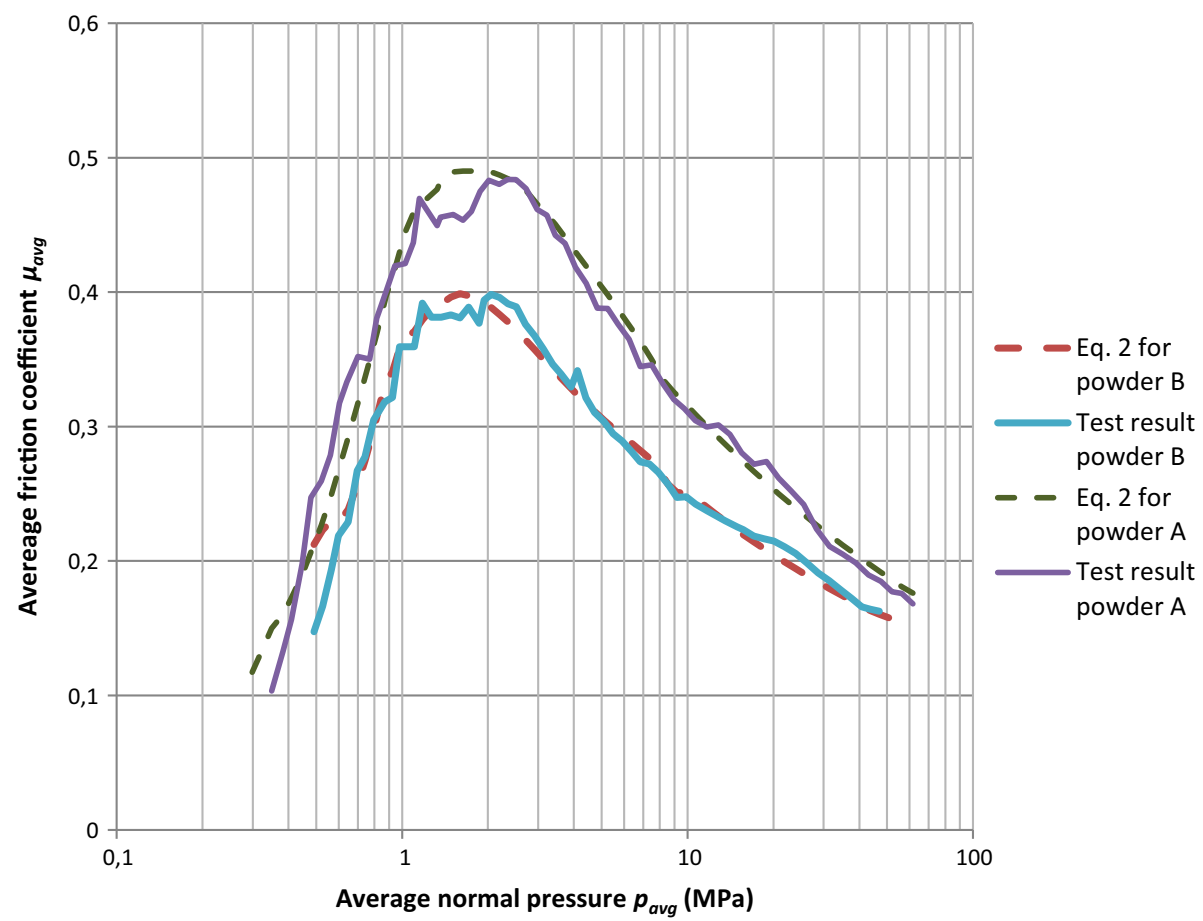

Fig. 12 Average friction coefficient $\mu_{\text {avg }}$ over total powder pillar from a loading test calculated according to Eq 1, respectively, Eq 2 and 5, for powder $\mathrm{A}$ and $\mathrm{B}$

ing, has been presented and applied.

- Stick phenomena and local effects have been investigated and can be disregarded in the present tests.

- The friction coefficient can be described as a function of normal pressure as shown by comparing forces from compaction with the forces determined during ejection.

\section{Open Access}

This article is distributed under the terms of the Creative Commons Attribution 4.0 International License (http://creativecommons.org/ licenses/by/4.0/), which permits unrestricted use, distribution, and reproduction in any medium, provided you give appropriate credit 


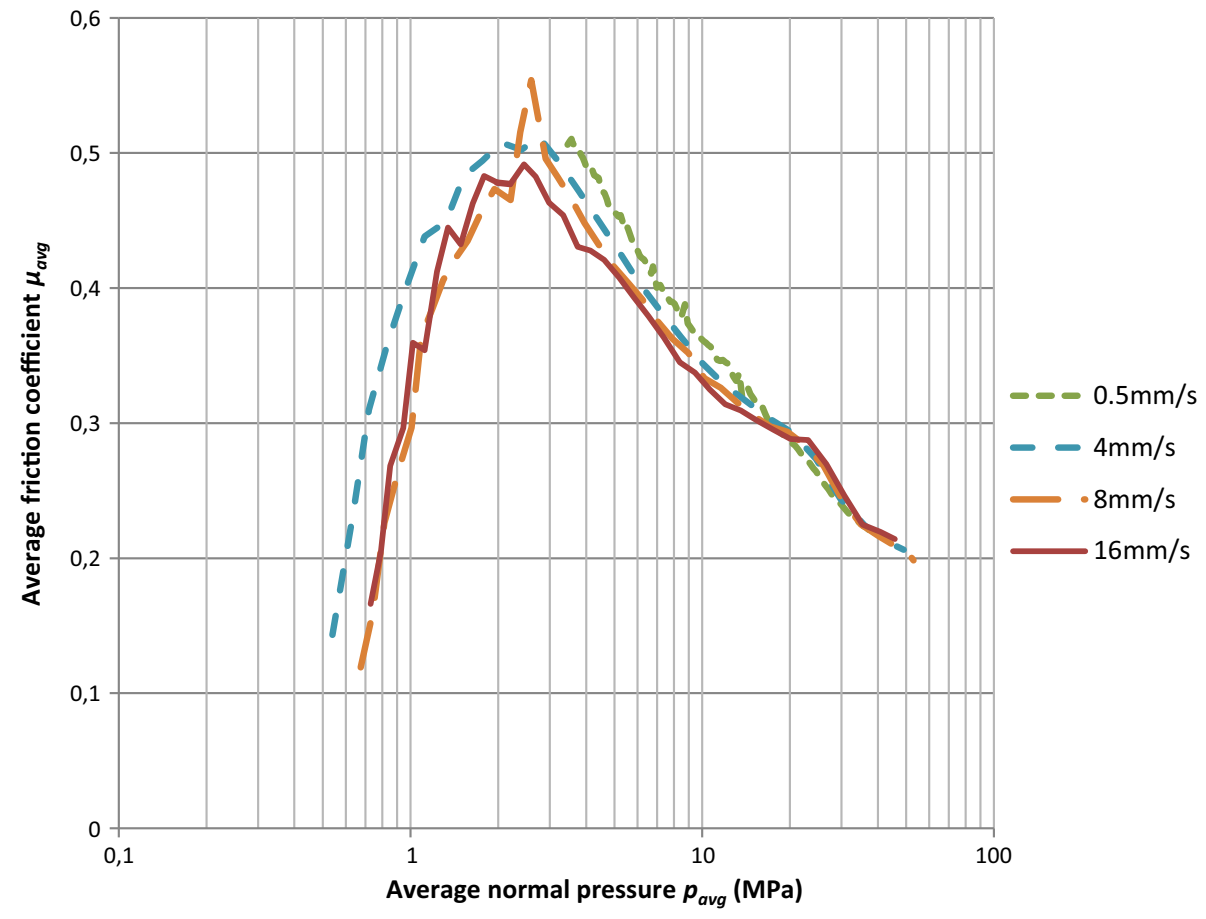

Fig. 13 Experimentally determined rate dependence on average friction coefficient $\mu_{\text {avg }}$

to the original author(s) and the source, provide a link to the Creative Commons license, and indicate if changes were made.

\section{References}

1. A. Michrafy, M.S. Kadiri, and J.A. Dodds, Wall Friction and its Effects on the Density Distribution in the Compaction of Pharmaceutical Excipients, Chem. Eng. Res. Des., 2003, 81(8), p 946-952

2. D. Korachkin, D.T. Gethin, R.W. Lewis, and J.H. Tweed, Friction Measurement and Lubrication in Unloading and Ejection Stages in Powder Pressing Cycle, Powder Metall., 2008, 51(1), p 14-30

3. İsmail Aydin, Brian J. Briscoe, and Kenan Y. Şanlitürk, Density Distributions During the Compaction of Alumina Powders: A Comparison of a Computational Prediction with Experiment, Comput. Mater. Sci., 1994, 3(1), p 55-68

4. H.M. Macleod, The Determination of Density Distribution in Ceramic Compacts Using Autoradiography, Powder Technol., 1977, 16(1), p $107-122$

5. J. Brandt, L. Nilsson, Simulating the powder compaction and sintering of cemented carbides with a unified FE-tool. On constitutive modelling of the compaction and sintering of cemented carbides, Linköping Studies in Science and Technology Dissertations No. 521, Linköping (1998)

6. B.J. Briscoe and S.L. Rough, The Effects of Wall Friction in Powder Compaction, Colloids Surf. A, 1998, 137(1), p 103-116

7. H. Staf, E. Olsson, P. Lindskog, and P.-L. Larsson, On RateDependence of Hardmetal Powder Pressing of Cutting Inserts, Powder Metall., 2017, 60(1), p 7-14

8. D.M.M. Guyoncourt, J.H. Tweed, A. Gough, J. Dawson, and L. Pater, Constitutive Data and Friction Measurements of Powders Using Instrumented Die, Powder Metall., 2001, 44(1), p 25-33

9. S.-T. Hong, Y. Hovanski, C.A. Lavender, and K.S. Weil, Investigation of Die Stress Profiles During Powder Compaction Using Instrumented Die, J. Mater. Eng. Perform., 2008, 17(3), p 382-386
10. P. Samuelsson and B. Bolin, Experimental Studies of Frictional Behavior of Hard Metal Powder Sliding on Cemented Carbide Walls, Scand. J. Metall., 1983, 12, p 315-322

11. S. Strijbos, Powder-Wall Friction: The Effects of Orientation of Wall Grooves and Wall Lubricants, Powder Technol., 1977, 18(2), p 209214

12. J.G. Wagner, The Frictional Behavior of Tungsten and Molybdenum Powders Sliding on Die Materials, Powder Technol., 1983, 35(1), p $47-50$

13. B. Wikman, N. Solimannezhad, R. Larsson, M. Oldenburg, and H.-A. Häggblad, Wall Friction Coefficient Estimation Through Modelling of Powder Die Pressing Experiment, Powder Metall., 2000, 43(2), p 132138

14. I.M. Cameron and D.T. Gethin, Exploration of Die Wall Friction for Powder Compaction Using a Discrete Finite Element Modelling Technique, Modell. Simul. Mater. Sci. Eng., 2001, 9(4), p 289-307

15. P. Lindskog, D.C. Andersson, and P.-L. Larsson, An Experimental Device for Material Characterization of Powder Materials, J. Test. Eval., 2013, 41(3), p 504-516

16. D.C. Andersson, P. Lindskog, and P.-L. Larsson, Inverse Modeling Applied for Material Characterization of Powder Materials, J. Test. Eval., 2015, 43, p 1005-1019

17. D.C. Andersson, P. Lindskog, H. Staf, and P.-L. Larsson, On Material Parameter Sensitivity at the Production of Hard Metal Components by Powder Compaction, J. Mater. Eng. Perform., 2014, 23(6), p 2199-2208

18. H. Staf, D.C. Andersson, P. Lindskog, and P.-L. Larsson, On the Influence of Material Parameters in a Complex Material Model for Powder Compaction, J. Mater. Eng. Perform., 2016, 25(10), p 4408-4415

19. H.-Å. Häggblad, Constitutive Models for Powder Materials, Powder Technol., 1991, 67(2), p 127-136

20. P. Jonsén and H.-Å. Häggblad, Modelling and Numerical Investigation of Residual Stress State in Green Metal Powder Body, Powder Technol., 2005, 155(3), p 196-208

21. E. Olsson and P.-L. Larsson, A Numerical Analysis of Cold Powder Compaction Based on Micromechanical Experiments, Powder Technol., 2013, 243, p 1185-1201 
22. C.L. Martin, D. Bouvard, and S. Shima, Study of Particle Rearrangement During Powder Compaction by the Discrete Element Method, $J$. Mech. Phys. Solids, 2003, 51(4), p 667-693

23. C.L. Martin and D. Bouvard, Study of the Cold Compaction of Composite Powders by the Discrete Element Method, Acta Mater. 2003, 51(2), p 373-386
24. E. Olsson and P.-L. Larsson, Micromechanical Investigation of the Fracture Behavior of Powder Materials, Powder Technol., 2015, 286, p 288-302

25. ABAQUS, Abaqus 6.14, Dassault Systèmes Simulia Corp, Providence, RI, USA (2014)

26. LS-Dyna Keyword User's Manual, Volume I, LSTC, Livermore, 2015, 6319, p. $591-736$ 